\title{
The application of a phycocyanin extract obtained from Arthrospira platensis as a blue natural colorant in beverages
}

\author{
Ana Belén García ${ }^{1}$ Eleonora Longo ${ }^{2} \cdot$ Ruperto Bermejo $^{1}[$ \\ Received: 15 February 2021 / Revised and accepted: 31 May 2021 / Published online: 21 July 2021 \\ (c) The Author(s) 2021, corrected publication 2021
}

\begin{abstract}
Currently, the food additive industry has interest in replacing artificial dyes with natural pigments, trying to maintain consumer interest and increase their awareness towards healthy diets. Phycobiliproteins are light-harvesting and water-soluble proteins extracted from cyanobacteria and red algae that can be employed as natural additives. In the present work, a C-phycocyanin extract from the cyanobacterium Arthrospira platensis was tested as blue colorant in beverages to demonstrate that samples containing the protein extract have a color similar to marketed beverages containing synthetic dyes. Using spectroscopy and colorimetry, the extract was characterized and gave evidence of having good properties and good stability in the $\mathrm{pH}$ range between 3.0 and 9.0. The staining factors, representing the amount of blue protein needed to reproduce the color of bluish commercial samples, ranged between 15.6 and $111.7 \mathrm{mg} \cdot \mathrm{L}^{-1}$, being sufficiently low in all samples. Additionally, color stability during a short period of cold storage was studied: it demonstrated that isotonic and tonic beverages remained stable throughout the 11-days analysis period with no significant changes. These results prove that the C-phycocyanin extract has potential applications in food as natural colorant, being an alternative option to synthetic coloring molecules.
\end{abstract}

Keywords C-phycocyanin $\cdot$ Colorimetry $\cdot$ Colored beverages $\cdot$ Natural food colorants $\cdot$ Color stability

\section{Introduction}

Cyanobacteria are oxygenic photosynthetic prokaryotes producing pigments such as chlorophyll, carotenoids, and phycobiliproteins (Prasanna et al. 2010). The phycobiliproteins are proteins that form light-harvesting antenna complexes (phycobilisomes) and act as photosynthetic accessory pigments in cyanobacteria, red algae, cryptomonads, and glaucophytes (MacColl 1998; Kannaujiya et al. 2017). These macromolecules are a family of hydrophilic, brilliantly colored, and

Ruperto Bermejo

rbermejo@ujaen.es

Ana Belén García

abgr0013@red.ujaen.es

Eleonora Longo

eleonora.longo@studenti.unipd.it

1 Department of Physical and Analytical Chemistry, Higher Engineering Polytechnic School of Linares, University of Jaen, 23700 Linares, Spain

2 Department of Pharmaceutical and Pharmacological Sciences, University of Padova, Padova, Italy stable fluorescent pigments proteins. Based on their absorption characteristics, phycobiliproteins are classified into: phycoerythrins (PEs), phycocyanins (PCs), and allophycocyanins (APCs) (Samsonoff and MacColl 2001; Bermejo and Ramos 2012). They consist of dissimilar $\alpha$ and $\beta$ polypeptide chains which probably originated from a common ancestor but apparently diverged early in evolution (Kaur et al. 2019). Because of their excellent spectroscopic properties, stability, high absorption coefficient, and high quantum yield, a wide range of promising applications of phycobiliproteins in biomedical research, diagnostics, and therapeutics has become possible (Glazer 1994; Chowdhury et al. 2007; Borowitzka 2013; Bharathiraja et al. 2016; Sonani 2016; Tavanandi et al. 2018). In addition, phycobiliproteins have potential as natural colorants to use in food, cosmetics, and pharmaceuticals, especially as substitutes for synthetic dyes, which are generally toxic or otherwise unsafe (Arad and Yaron 1992; Sinha et al. 2011; Kaur et al. 2019). Particularly, great importance has to be given to C-phycocyanin (C-PC) because of its various medical and pharmacological properties, showing a therapeutic value thanks to its protective effect and anticarcinogenic 
activity (Rimbau et al. 1999), its antioxidative and antiinflammatory activities (Benedetti et al. 2006), and its potential use in the treatment of Alzheimer's and Parkinson's disease (Rimbau et al. 2001). Regarding color application, C-PC is largely employed for the replacement of synthetic pigments in different products such as chewing gums, ice cream, candies, soft drinks, dairy products, and cosmetics (lipsticks and eyeliners) (Sekar and Chandramohan 2008; Moreira 2012; Campos Assumpção de Amarante et al. 2020; Galetovic et al. 2020).

Coloring additives are dyes that confer color to food, drinks, or drugs to which they are added. Color of food and drinks has an important impact on consumers since it is one of the first characteristics perceived for products. According to the European Food Safety Authority (EFSA), food colorants are one category of food additives that is used in the food industry to render processed foods more attractive, to restore the color of food after processing, and to give color to otherwise colorless food. Food colorants can be divided in two groups depending on their origin: synthetic and natural colorants (Carocho et al. 2014). In general terms, synthetic molecules are more stable than natural ones, maintaining their coloration for a longer time. However, some of them have been reported to be toxic or otherwise unsafe (Mahmoud and Org 2006; Hashem et al. 2019). As such, there is an increasing interest in finding non-harmful alternative molecules, and natural colorants have gained more interest among consumers who demand natural products. Unfortunately, natural colorants might be sensitive to light exposure, might change color when exposed to different $\mathrm{pH}$, and degrade at high temperatures. Additionally, they are generally available in a limited color range. All of these factors limit the use of natural colorants at the industry level, so that there is a demand for new natural colorants to be used as food additives and extend the coloring range of natural food dyes.

In this context, several studies have focused on the use of natural colorants in food and drinks, especially on aspects of preparation, characterization, application, stability, kinetics, and color evaluation (Lobo et al. 2018; Montibeller et al. 2018; Chen et al. 2019; Ngamwonglumlert et al. 2020; Pereira et al. 2020). There are many works that report the use of natural compounds in dairy products, bakery products, soft drinks, and candies (Mezquita et al. 2015; Gengatharan et al. 2017; Almeida et al. 2018; Da Silva et al. 2019; Leong et al. 2019; Otálora et al. 2019; Pires et al. 2020). Regarding phycobiliproteins, they have been incorporated in desserts, puddings, sourdough, soft drinks, and dairy products, although their use needs to be further supported by toxicity testing. Moreover, additional research focusing on the bioavailability and the interaction of phycobiliproteins with food, beverages, matrixes, and stabilizers, among others, is required (Moreira et al. 2012; Dewi et al. 2018; Chentir et al.
2019; Hsieh-Lo et al. 2019; Niccolai et al. 2019; Galetovic et al. 2020; García et al. 2021).

On the other hand, blue colors are not uncommon in nature, but their replication in food may be difficult due to the low $\mathrm{pH}$, light, and heat stability of natural compounds that produce blue tones (Newsome et al. 2014). C-phycocyanin, a natural blue molecule belonging to the phycobiliproteins group, has been studied as natural colorant mainly for dairy products and yogurts (Moreira et al. 2012; Dewi et al. 2018; Kaur et al. 2019; Mohammadi-Gouraji et al. 2019; Campos Assumpção de Amarante et al. 2020). However, some authors claim that the use of this protein in food and beverages is limited by the lack of stability to heat, light, and acidic conditions (Jespersen et al. 2005; Newsome et al. 2014). Only a few studies have evaluated the color stability of C-PC after its application (Dewi et al. 2018; Kaur et al. 2019; Mohammadi-Gouraji et al. 2019). Another pivotal reason for trying to exploit this natural dye is its antioxidant, anticancer, and anti-inflammatory effects reported by several studies (Romay et al. 1998; Sonani et al. 2017; Fernandes e Silva et al. 2018), which would add value to the obtained products. Furthermore, this compound has fewer side effects than chemical drugs, and algae are ecofriendly sources receiving increasing attention.

In light of the above and considering the growing demand for natural colorants and functional foods by consumers, we have focused our attention on using a phycocyanin extract as natural blue colorant. In the present work, a C-phycocyanin extract (C-PC extract) with food grade purity from the cyanobacterium Arthrospira platensis was studied as a natural colorant in different beverages such as isotonic and tonic drinks and wine. This study represents a first approach that aims to characterize the C-PC extract by spectroscopy in order to understand the coloring properties of the protein solution. Additionally, a colorimetric study was developed for the color evaluation of samples containing the natural protein extract which reproduce the color of commercially available products. Hence, the outcome of this study would enhance the organoleptic and nutritional properties of beverages using a C-PC extract from cyanobacteria.

\section{Materials and methods}

\section{Production of phycocyanin extract}

The C-phycocyanin extract was obtained using the corresponding methodology (Ramos et al. 2011; Bermejo and Ramos 2012) from cells of the cyanobacteria Arthrospira platensis, generously provided by the company Imade S.L. (Granada, Spain). The phycobiliprotein solution was extracted from the lyophilized cyanobacteria using $0.1 \mathrm{M}$ phosphate buffer ( $\mathrm{pH}$ 7.0) and mixing the biomass 
with the liquid for reconstitution in a ratio of 1:20 (w/v). The slurry was agitated for $30 \mathrm{~min}$ at constant speed by a Heidolph RZR1 (Germany) variable-speed magnetic stirrer, and the intracellular material was obtained disrupting the cell wall by osmotic shock. The sample was centrifuged at $14,500 \times g$ for $15 \mathrm{~min}$ to recover the phycobiliproteins in the supernatant. The supernatant was precipitated with $70 \%$ saturation ammonium sulphate $\left(\left(\mathrm{NH}_{4}\right)_{2} \mathrm{SO}_{4}\right)$ and left to stand overnight in the dark at $4{ }^{\circ} \mathrm{C}$ before centrifugation. The pellets of purified biliproteins were resuspended in a small volume of the suitable buffer, dialyzed overnight at $4{ }^{\circ} \mathrm{C}$ against the same buffer. The concentrated protein solution was placed in a clean container, and $1 \% w / w$ of citric acid was added as preservative. The sample was stored at $4{ }^{\circ} \mathrm{C}$.

\section{Characterization of the C-phycocyanin extract}

Absorbance spectra were recorded on the UV-visible spectrophotometer (Lambda 20, Perkin Elmer, software UV Data Manager, USA) between 250 and $700 \mathrm{~nm}$. Fluorescence spectra were recorded on a spectrofluorimeter (FP-6500, Jasco, software Spectra Manger, Spain) between 550 and $700 \mathrm{~nm}$. Recording the absorption and fluorescence spectra of aqueous solutions in a large $\mathrm{pH}$ range served to monitor the influence of $\mathrm{pH}$ on the stability of the spectral parameters of the C-PC extract. The protein extract was dissolved in $20 \mathrm{mM}$ phosphate buffer at different $\mathrm{pHs}$ (ranging between 1.0 and 13.0) to achieve an appropriate concentration. Absorption spectra of the C-PC extract were determined after gradual falls or increases in $\mathrm{pH}(\mathrm{pH}$ 7-1 and $\mathrm{pH} 7-12$ ), and the stability was monitored by measuring the absorbance at $616 \mathrm{~nm}$. Fluorescence spectra were determined with the same solutions, and fluorescence intensity at $638 \mathrm{~nm}$ was registered. All spectra were recorded at room temperature.

The amounts of different phycobiliproteins in the C-PC extract were calculated from measurements of the absorbance at different wavelengths using the following equations (Bennett and Bogorad 1973):

$C-P C\left(m g \cdot m L^{-1}\right)=\frac{A_{615}-0.474 \cdot\left(A_{652}\right) A_{615}-0.474 \cdot\left(A_{652}\right)}{5.34}$

$\operatorname{APC}\left(m g \cdot m L^{-1}\right)=\frac{A_{652}-0.208 \cdot\left(A_{615}\right)}{5.09}$

$P E\left(m g \cdot m L^{-1}\right)=\frac{A_{563}-2.41 \cdot(P C)-0.849 \cdot(A P C)}{9.62}$

\section{Beverage samples}

Beverage samples were constituted by drinks (isotonic and tonic beverages and wine) available in grocery stores. The selected commercial products have a blue color; while standard products do not carry any coloring additive and therefore have no color. It is important to highlight that the same brand of beverage without the blue colorant additive was used as standard. Different commercial products were utilized to simulate colors using the blue C-PC extract: four isotonic drinks, two tonic drinks, and one wine. Storage of the samples was done in a domestic refrigerator at $5 \pm 2{ }^{\circ} \mathrm{C}$.

Only tonic drinks and wine were manipulated before the colorimetric analysis due to their gassed nature, as it was necessary to eliminate gas bubbles by stirring. They were placed on a magnetic stirrer for 20 min to obtain a liquid matrix without gas. The blue protein extract was added to the beverages under constant stirring to allow its homogenous mixing.

\section{Viscosity measurements}

The viscosity of beverages samples was measured using a Cannon Fenske Routine size 50 U-tube viscometer (PSL Ltd., UK) that was held in a water bath at the required temperature with a measurement accuracy of $\pm 0.1{ }^{\circ} \mathrm{C}$ (Selecta VB-1423, Spain). Water was used as the calibration fluid for the viscometer. The estimated uncertainty, based on repeated measurements, was $\pm 0.00002 \mathrm{P}$ (Poise) $\left(\mathrm{g} \mathrm{cm}^{-1} \mathrm{~s}^{-1}\right)$. All viscosity measurements were carried out on the same day of the preparation of the samples.

\section{Color evaluation}

Colorimetry was performed using a colorimeter (CM-5, Konica Minolta, data software CM-S100W SpectraMagic TM NX, Version 2.2, Japan) operated in the transmittance mode. All tests were run in $10 \mathrm{~mm}$ polystyrene sample cuvettes. The color was registered according to the CIELAB color space, and the following color space values were obtained: $\mathrm{L}^{*}$, representing the light-dark pair (lightness); $\mathrm{a}^{*}$, representing the red-green pair (redness); and $b^{*}$, representing the yellow-blue pair (yellowness). The recommended illuminant/observer pair D65/10 $0^{\circ}$ was used.

First, the color of the reference product (commercial product) was registered on the colorimeter, followed by registration of the color of the standard sample (sample to be added with C-PC extract). Successively, a few microliters of C-PC extract were added to the standard sample, and the color change was registered. After each C-PC extract addition, the color difference between the alimentary commercial product and the colored sample was defined by $\Delta \mathrm{E}^{*} \mathrm{ab}$. For determining the CIELAB color difference $\Delta \mathrm{E}^{*} \mathrm{ab}$, the following equation was used:

$$
\begin{aligned}
\Delta E_{a b}^{*} & =\sqrt{\left(\Delta L^{*}\right)^{2}+\left(\Delta a^{*}\right)^{2}+\left(\Delta b^{*}\right)^{2}} \\
& =\sqrt{\left(L_{i}^{*}-L_{0}^{*}\right)^{2}+\left(a_{i}^{*}-a_{0}^{*}\right)^{2}+\left(b_{i}^{*}-b_{0}^{*}\right)^{2}}
\end{aligned}
$$


where $L_{0}^{*}, a_{0}^{*}$, and $b_{0}^{*}$ were the values of the drink commercial product and $L_{i}^{*}, a_{i}^{*}$, and $b_{i}^{*}$ were the measured values of each sample added with the C-PC extract. Color data were recorded and color change and color space values calculated on triplicate samples for all conditions assessed throughout this study.

\section{Statistical analysis}

Data were statistically analyzed by one-way analysis of variance (ANOVA) using the SPSS program (IBM SPSS statistics 22$)$. Tukey's HSD test $(\mathrm{P}<0.05)$ was used to test the significance of differences between isotonic and tonic drinks. Data are presented as the mean \pm SD of three independent experiments with three replicates in each experiment.

\section{Results}

\section{Characterization of the C-phycocyanin extract}

The absorbance spectrum of the coloring extract shows a main peak at $616 \mathrm{~nm}$ (Fig. 1a). Preliminary analysis for the estimation of the phycobiliproteins content in the extract revealed that this coloring extract solution contained $3.67 \mathrm{mg} \mathrm{C}-\mathrm{PC} \cdot \mathrm{mL}^{-1}$ as the major component $(96.3 \% \mathrm{w} / \mathrm{w})$. Other proteins are present in a significantly minor proportion, such as APC $(3.7 \% w / w)$. Regarding fluorescence, the corresponding spectrum (Fig. 1a) shows a maximal fluorescence intensity emission at $638 \mathrm{~nm}$.

UV-Vis spectroscopy and fluorescence spectroscopy were used to determine the stability of the blue C-PC extract and its optimal $\mathrm{pH}$ range of application, with C-PC excited at $590 \mathrm{~nm}$ to record the fluorescence spectra of the protein extract at different pHs (Fig. 1b, c). At neutral pH, the fluorescence maximum was at $638 \mathrm{~nm}$.

Additionally, the C-PC extract was analyzed to register color parameters as a function of $\mathrm{pH}$ according to the Color Space defined by the International Commission on Illumination (CIELAB color system: $\mathrm{L}^{*}, \mathrm{a}^{*}$, and $\mathrm{b}^{*}$ values). The results are summarized in Table 1.

\section{Pigmentation of beverage samples with the C-PC extract}

In coloring studies, the standard marketed product was colored with the blue C-PC extract to achieve the most similar color to the one of the reference product. From coloring assays, a coloring curve is obtained: it plots the difference in color $\left(\Delta \mathrm{E}^{*} \mathrm{ab}\right)$ between the sample and the reference against the volume of C-PC extract added to the standard product $(\mu \mathrm{L})$. In order to match the color of marketed products in the three types of beverages, it was (a)

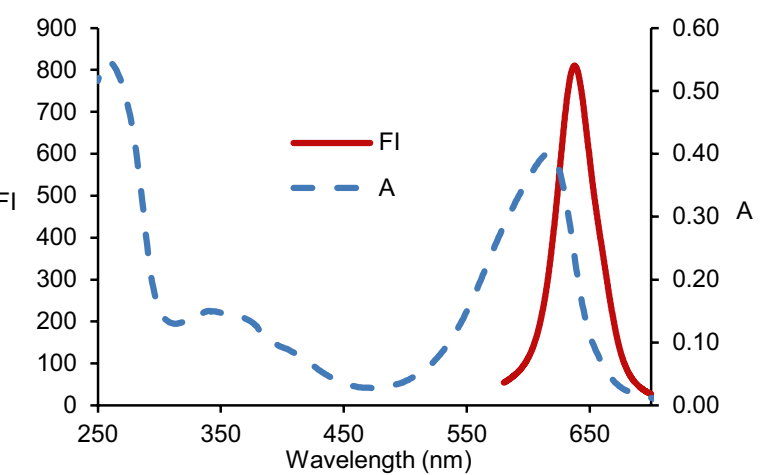

(b)

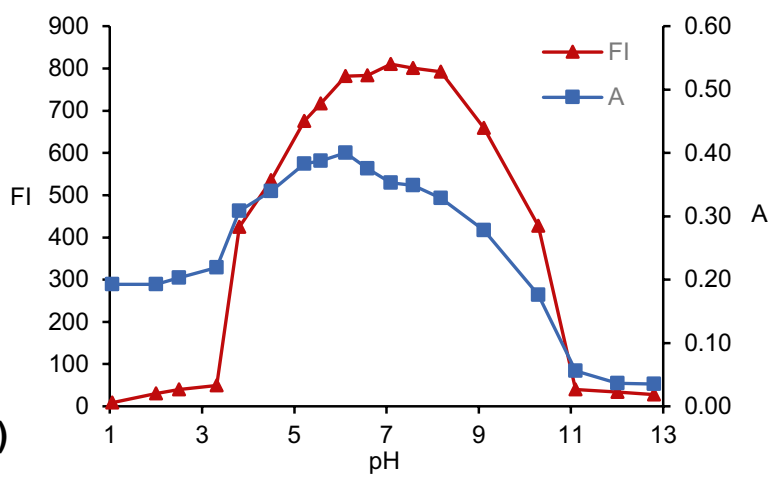

(c)

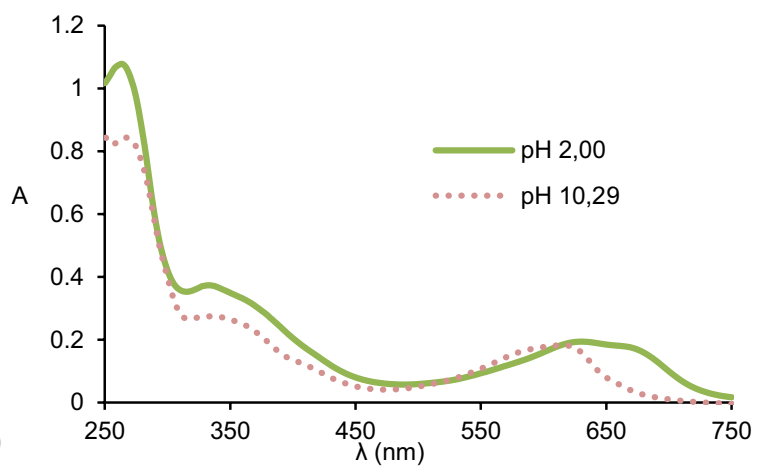

Fig. 1 a Absorption and fluorescence spectra of the C-PC extract from $S$. platensis at $\mathrm{pH}=7.0 ;$ b variation of absorbance ( $\square$ ) (at $616 \mathrm{~nm}$ ) and relative fluorescence intensity ( $\Delta$ ) (at $638 \mathrm{~nm}$ ) of the C-PC extract solution at various $\mathrm{pH}$ values in $20 \mathrm{mM}$ phosphate buffer; $\mathbf{c}$ absorbance spectra of C-PC extract at $\mathrm{pH}$ values of 2.00 and 10.29. For absorbance and fluorescence measurements, the protein concentration was $0.03 \mathrm{mg} \mathrm{C}-\mathrm{PC} \mathrm{mL} \mathrm{mL}^{-1}$

necessary to add a specific volume of C-PC extract to the $14 \mathrm{~mL}$ of the beverage (Table 2). For each sample, staining factors were calculated as the total amount of C-PC protein per liter (of product) needed to obtain a color similar to that of the reference commercial product, represented by the minimum value of $\Delta \mathrm{E}^{*} \mathrm{ab}$. Figure 2 shows a presentation of the samples colored with the C-PC extract compared to the reference product found on the market.

Four different commercial isotonic beverages were studied for testing the potential coloring capacity of the C-PC extract (Table 2, Fig. 3). In the same way, two commercial 
Table 1 Color parameters (CIELAB-color system) for the C-PC extract at different $\mathrm{pH}$ values, as mean $\pm \mathrm{SD}$ of three sample replicates. $L^{*}, a^{*}$, and $b^{*}$ are the three CIELAB values to defining the color

\begin{tabular}{|c|c|c|c|}
\hline $\mathrm{pH}$ & $\mathrm{L}^{*}(\mathrm{D} 65)$ & $a^{*}(\mathrm{D} 65)$ & $\mathrm{b}^{*}(\mathrm{D} 65)$ \\
\hline 1 & $94.04 \pm 0.02$ & $-7.90 \pm 0.03$ & $0.98 \pm 0.03$ \\
\hline 1.5 & $93.95 \pm 0.04$ & $-7.49 \pm 0.02$ & $1.08 \pm 0.02$ \\
\hline 2 & $93.22 \pm 0.10$ & $-7.26 \pm 0.03$ & $1.31 \pm 0.05$ \\
\hline 2.5 & $91.43 \pm 0.03$ & $-9.50 \pm 0.06$ & $-1.97 \pm 0.05$ \\
\hline 3 & $88.35 \pm 0.08$ & $-15.16 \pm 0.10$ & $-8.85 \pm 0.08$ \\
\hline 3.5 & $88.29 \pm 0.03$ & $-15.35 \pm 0.08$ & $-9.84 \pm 0.05$ \\
\hline 4 & $88.16 \pm 0.11$ & $-15.50 \pm 0.15$ & $-9.79 \pm 0.10$ \\
\hline 5 & $88.24 \pm 0.06$ & $-15.41 \pm 0.07$ & $-9.94 \pm 0.07$ \\
\hline 6 & $88.27 \pm 0.05$ & $-15.39 \pm 0.04$ & $-9.92 \pm 0.03$ \\
\hline 7 & $88.40 \pm 0.04$ & $-15.07 \pm 0.02$ & $-9.68 \pm 0.03$ \\
\hline 8 & $88.84 \pm 0.06$ & $-14.05 \pm 0.01$ & $-8.73 \pm 0.07$ \\
\hline 9 & $88.38 \pm 0.08$ & $-14.93 \pm 0.02$ & $-9.54 \pm 0.02$ \\
\hline
\end{tabular}

Table 2 Staining factors of the assayed beverages: data obtained from the coloring curves of products (Figs. 2 and 3) ([C-PC] extract $=3.67 \mathrm{mg} \mathrm{mL}^{-1}$ )

\begin{tabular}{llllr}
\hline Product & $\begin{array}{l}\text { Commercial } \\
\text { brand }\end{array}$ & $\begin{array}{l}\text { Extract } \\
\text { volume added } \\
(\mu \mathrm{L})\end{array}$ & $\begin{array}{l}\Delta \mathrm{E}^{*} \mathrm{ab} \\
\text { Reached }\end{array}$ & $\begin{array}{l}\text { Staining } \\
\text { factor } \\
\left(\mathrm{mg} \cdot \mathrm{L}^{-1}\right)\end{array}$ \\
\hline Isotonic drinks & $\mathrm{A}$ & 420 & 7.94 & 106.74 \\
& $\mathrm{~B}$ & 380 & 6.04 & 96.84 \\
& $\mathrm{C}$ & 440 & 6.70 & 111.67 \\
& $\mathrm{D}$ & 130 & 6.21 & 33.72 \\
Tonic drinks & $\mathrm{E}$ & 60 & 4.97 & 15.64 \\
& $\mathrm{~F}$ & 90 & 4.97 & 23.41 \\
Wine & $\mathrm{G}$ & 240 & 5.17 & 61.76 \\
\hline
\end{tabular}

I-D

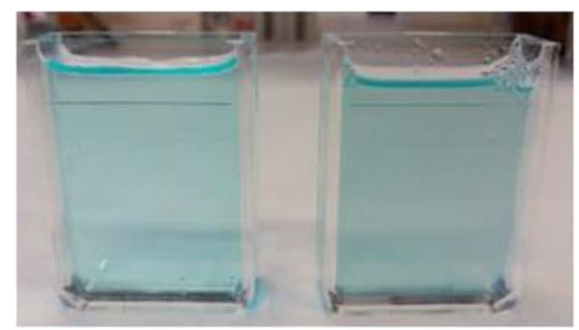

T-E

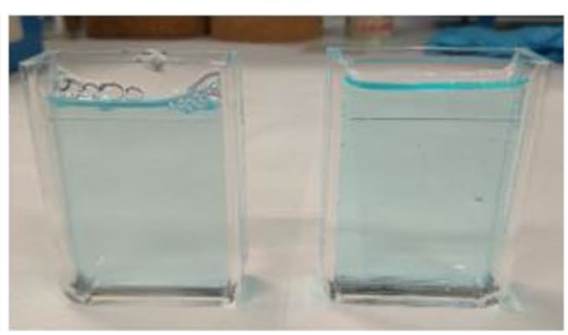

tonic beverages and one blue wine were chosen for studying this capacity in other media (Table 2, Fig. 4).

Viscosity measurements were carried out to determine the viscosity of commercially available samples and those generated by the addition of the C-PC extract (Table 3).

\section{Stability studies of colored beverages samples}

Regarding food products, the other pivotal aspect that must be taken into account is the stability, and because of that, color stability determinations were developed for beverages added with the C-PC extract. Figure 5 shows variations of the color coordinates $\mathrm{L}^{*}, \mathrm{a}^{*}$, and $\mathrm{b}^{*}$, as well as the color difference $\Delta \mathrm{E}^{*} \mathrm{ab}$ registered for isotonic, tonic, and wine samples with C-PC extract added. Samples were controlled over the storage period of 11 days. The samples selected for each type of beverage were obtained by the addition of the C-PC extract to reproduce the color of the " $\mathrm{D}$ " isotonic beverage, the "E" tonic beverage, and the "G" wine. Table 4 shows the results of the statistical analysis on the stability between tonic and isotonic beverages.

\section{Discussion}

The C-PC extract from Arthrospira platensis is composed mainly of C-phycocyanin (C-PC) and allophycocyanin (APC) (Bermejo et al. 2006; Bermejo and Ramos 2012). The $\mathrm{C}$-phycocyanin purity grade is defined by the ratio between its peak absorbance at $616 \mathrm{~nm}$ and the absorbance of proteins at $280 \mathrm{~nm}\left(\mathrm{~A}_{616} / \mathrm{A}_{280}\right)$. When this ratio is $\geq 0.7$, it is considered as food grade purity (Rito-Palomares et al. 2001; Campos Assumpção de Amarante et al. 2020). The C-PC extract used in this work had a purity ratio of 0.96 , which was more than sufficient to be used in the tests as a food coloring agent.

When the absorbance ratio is lower than 4 , it indicates the presence of other proteins, therefore that the solution
Fig. 2 Photographs showing a vivid presentation of the marketed beverages and beverages obtained using the C-PC extract as natural colorant. In the figure, three representative samples are shown: sample $\mathrm{D}$, representing isotonic beverages (I-D); sample E, representing tonic beverages $(\mathrm{T}-\mathrm{E})$; and sample $\mathrm{G}$, representing wine $(\mathrm{W}-\mathrm{G})$. For each pair, the reference product is on the left and the sample added with the C-PC extract is on the right 


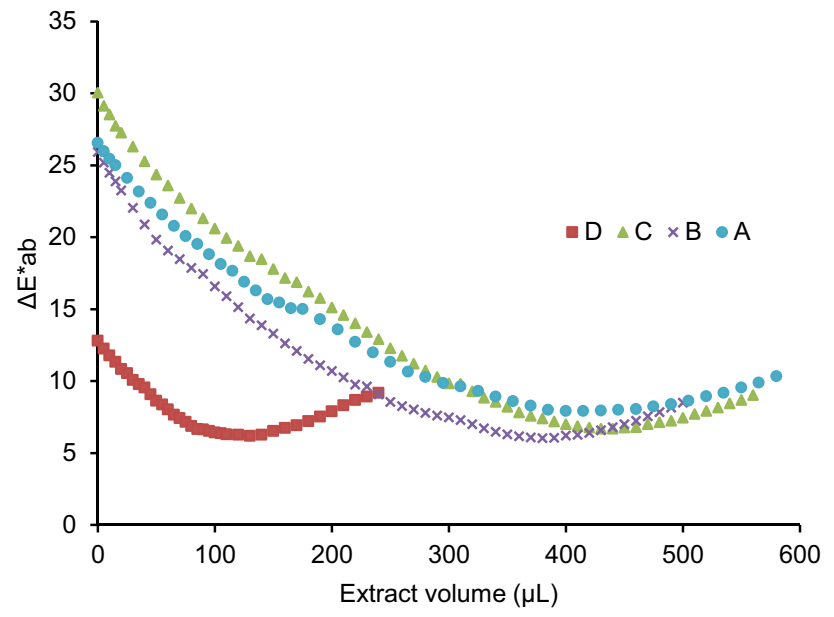

Fig. 3 Coloring curves of isotonic beverages resulted from coloring assays using the C-PC extract from S. platensis $\left([\mathrm{C}-\mathrm{PC}]_{\text {extract }}=3.67 \mathrm{mg} \mathrm{mL}^{-1}\right.$ )

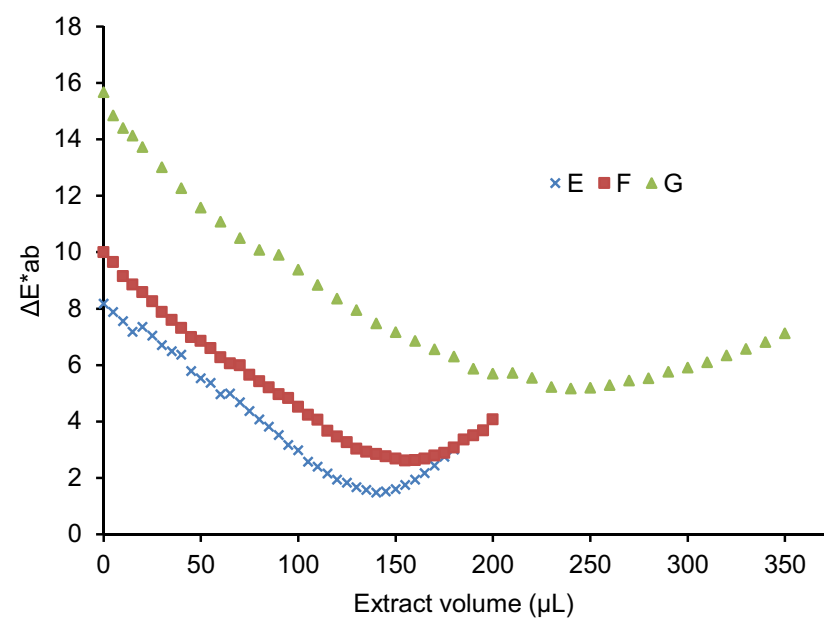

Fig. 4 Coloring curves of tonic and wine beverages resulted from coloring assays using the C-PC extract from S. platensis $\left([\mathrm{C}-\mathrm{PC}]_{\text {extract }}=3.67 \mathrm{mg}\right.$ C-PC $\mathrm{mL}^{-1}$ )

is not a pure C-PC solution. In this case, APC is present in a minor proportion, not having significant repercussions on the final blue color of the C-PC extract: APC is also a blue protein, characterized by having a blue color lighter than the one of C-PC. The protein extract obtained in this study is mostly constituted by C-PC thanks to the removal of contaminant proteins by precipitation with ammonium sulphate. A small shoulder is observed at $650 \mathrm{~nm}$, which corresponds to the APC absorbance maximum. Both absorption and fluorescence spectra of the C-PC extract demonstrate that $\mathrm{C}$-phycocyanin is the main protein found and therefore the predominant one in the extract, conferring its characteristic and attractive deep dark blue
Table 3 Viscosity measurements of beverages: data are recorded for marketed products and for samples added with the C-PC extract as per coloring studies (Figs. 2 and 3). Data are represented with mean, and the standard deviations obtained were 0.0001 and 0.00002 for density and viscosity, respectively. *Standard product; **standard product added with C-PC extract

\begin{tabular}{llll}
\hline Sample & Density $\left(\mathrm{g} \cdot \mathrm{cm}^{-3}\right)$ & $\begin{array}{l}\text { Kinematic viscosity } \\
\left(\mathrm{cm}^{2} \cdot \mathrm{s}^{-1}\right)\end{array}$ & $\begin{array}{l}\text { Dynamic } \\
\text { viscosity } \\
\left(\mathrm{g} \cdot \mathrm{cm}^{-1} \cdot \mathrm{s}^{-1}\right)\end{array}$ \\
\hline $\mathrm{D}$ & 1.025 & 0.0101 & 0.0103 \\
$\mathrm{D}^{*}$ & 1.019 & 0.0098 & 0.0010 \\
$\mathrm{D}^{* *}$ & 1.019 & 0.0102 & 0.0104 \\
$\mathrm{E}$ & 1.037 & 0.0112 & 0.0116 \\
$\mathrm{E}^{*}$ & 1.031 & 0.0108 & 0.0111 \\
$\mathrm{E}^{* *}$ & 1.031 & 0.0108 & 0.0111 \\
$\mathrm{G}$ & 1.015 & 0.0138 & 0.0140 \\
$\mathrm{G}^{*}$ & 1.013 & 0.0137 & 0.0140 \\
$\mathrm{G}^{* *}$ & 1.019 & 0.0135 & 0.0138 \\
\hline
\end{tabular}

color, while allophycocyanin (APC) appears in a small proportion.

Protein solubility and stability will depend on factors such as the composition and $\mathrm{pH}$ of the beverages tested. In this sense, wine is an alcoholic matrix that is different from tonic and isotonic beverages that are more similar. Depending on the commercial brand, isotonic drinks usually have a composition based on a mixture of various components: carbohydrates, acidifiers, minerals, vitamins, etc. On the other hand, tonics are usually simple in composition, consisting only of carbonated water with dissolved quinine.

Regarding $\mathrm{pH}$, this is a relevant factor that influences the stability of phycobiliproteins. The beverage samples utilized in this work had $\mathrm{pH}$ values of 3.0 for isotonic and tonic drinks and a $\mathrm{pH}$ of 3.2 for the wine sample. Accordingly, the behavior of the colorant extract inside beverage samples presenting these $\mathrm{pH}$ values has to be known. When the coloring extract is mixed with phosphate buffer at $\mathrm{pH}$ values below 3.0, proteins aggregates form immediately. This is explained by the precipitation of proteins due to the very acidic $\mathrm{pH}$ of the solution. A similar behavior was obtained when the C-PC extract was tested in markedly alkaline solutions at $\mathrm{pH}$ values above 10: proteins are unstable, and the spectrum of the extract does not retain any shape, being completely disrupted and having a wide non-characteristic profile as showed for solutions at $\mathrm{pH} 2$ and $\mathrm{pH} 10.29$ (Fig. 1c). Therefore, the C-PC coloring extract was spectroscopically measured in the range from $\mathrm{pH} 1.0$ to 13.0. Every extract sample presents a characteristic absorbance peak at $616 \mathrm{~nm}$ and a second peak at $280 \mathrm{~nm}$ (total proteins peak). The absorbance spectrum preserves its characteristic profile when the $\mathrm{pH}$ of the protein solution is between 2.5 and 9.0. Although the absorbance values at the absorption 
Fig. 5 Changes in color indexes $\left(L^{*}, a^{*}, b^{*}\right.$, and $\Delta E^{*} a b$ are the CIELAB color system values) of the isotonic beverage ( $\square$ ), the tonic beverage $(\diamond)$, and the wine $(\triangle)$ pigmented with the C-PC extract during a short period of cold storage. The plotted values are the means of triplicate \pm standard deviations. Graphs show changes in $\Delta \mathrm{E}^{*} \mathrm{ab}$ (a); changes in $\mathrm{L}^{*}(\mathbf{b})$; changes in $\mathrm{a}^{*}(\mathbf{c})$, and changes in $\mathrm{b}^{*}(\mathbf{d})$

Table 4 Results of analysis of variance of the studied color parameters: a comparison between isotonic and tonic beverages during stability study
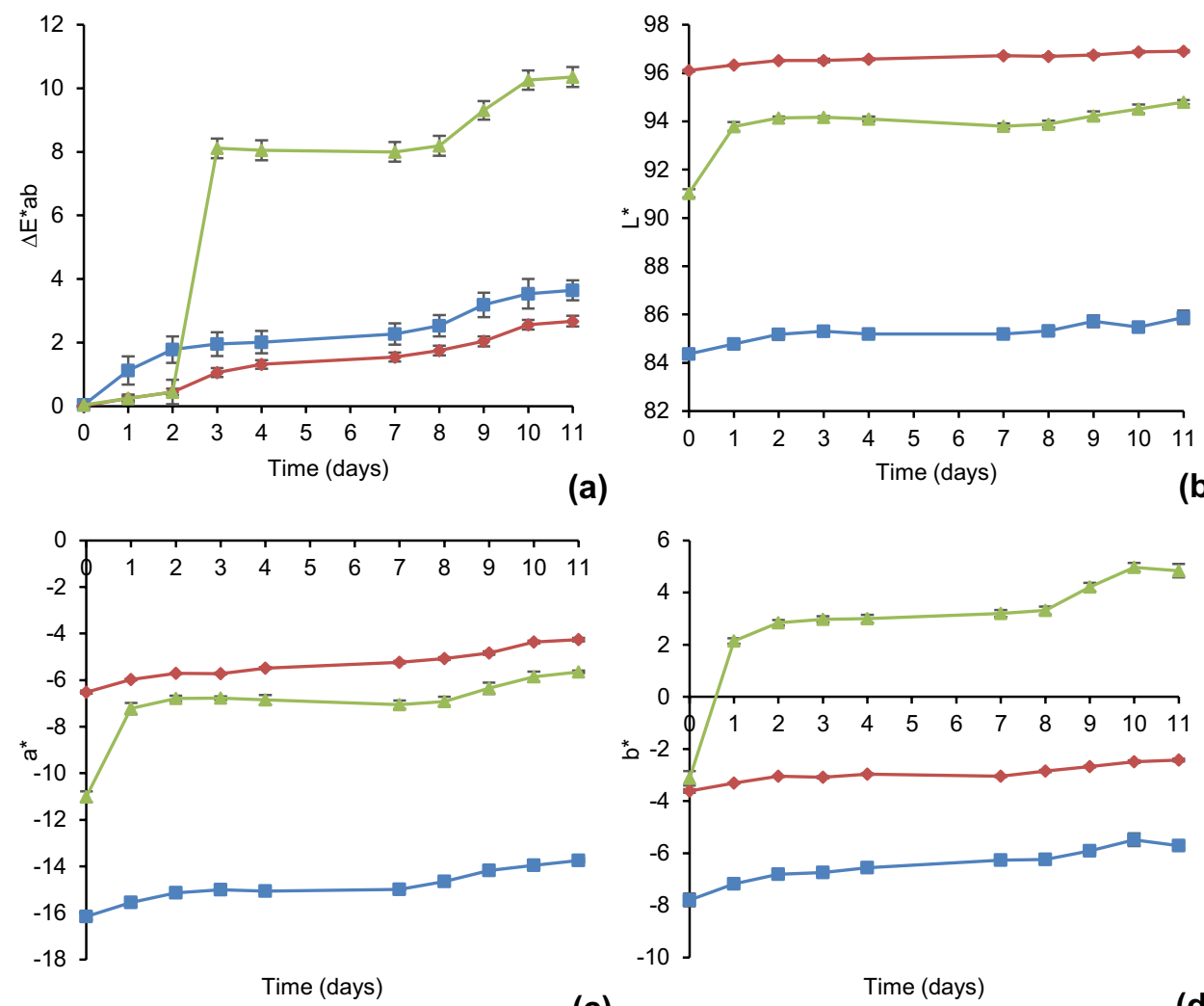

(c)

(d)

\begin{tabular}{lllll}
\hline Sample & $\mathrm{a}^{*}$ & $\mathrm{~b}^{*}$ & $\mathrm{~L}^{*}$ & $\Delta \mathrm{E}^{*} \mathrm{ab}$ \\
\hline ISOTONIC $^{\mathrm{a}}$ & $-14.32 \pm 0.38 \mathrm{a}$ & $-6.29 \pm 1.69 \mathrm{a}$ & $85.91 \pm 0.47 \mathrm{~b}$ & $2.06 \pm 0.21 \mathrm{a}$ \\
TONIC $^{\mathrm{a}}$ & $-5.23 \pm 0.12 \mathrm{~b}$ & $-2.90 \pm 0.05 \mathrm{~b}$ & $96.63 \pm 0.04 \mathrm{a}$ & $1.45 \pm 0.16 \mathrm{~b}$ \\
& $\mathrm{~F} 465.489$ & $\mathrm{~F} 319.707$ & $\mathrm{~F} 437.855$ & $\mathrm{~F} 4.877$ \\
& $\mathrm{gl}(1,58)$ & $\mathrm{gl}(1,58)$ & $\mathrm{gl}(1,58)$ & $\mathrm{gl}(1,58)$ \\
& $\mathrm{P} \leq 0.001$ & $\mathrm{P} \leq 0.001$ & $\mathrm{P} \leq 0.001$ & $\mathrm{P} 0.031$ \\
\hline
\end{tabular}

${ }^{a}$ Means followed by different letter in a column are significantly different at $5 \%$ level Tukey test $(\mathrm{P} \leq 0.05)$ maximum $(616 \mathrm{~nm})$ decrease at $\mathrm{pH}$ values lower than 4 (Fig. 1b), the absorbance spectrum profile remains the same as that of the protein at $\mathrm{pH} 7$, until values of $\mathrm{pH}$ below 3 are reached. The fluorescence spectrum maintains its profile and registers high values of fluorescence intensity (FI) between $\mathrm{pH} 4.0$ and 10.0. The intensity of the fluorescence peak decreases at $\mathrm{pH}$ lower than 5 and higher than 9. The dependence of the fluorescence intensity on $\mathrm{pH}$ values is in accordance with stability studies previously performed on C-phycocyanin from A. platensis (Couteau et al. 2004; Patel et al. 2004; Antelo et al. 2008) and is similar to what observed for C-phycocyanin from Atacama cyanobacteria (Galetovic et al. 2020).

It is well known that protein solubility is influenced by amino acid composition and sequence, molecular weight, conformation, and content of polar and nonpolar groups in amino acids. In this sense, protein solubility is affected by environmental factors such as ionic strength, type of solvent, $\mathrm{pH}$, temperature, and processing conditions. Regarding $\mathrm{pH}$, this factor is a crucial aspect to be taken into account in protein solubility. In accordance with the outcomes reached in this work, at extreme $\mathrm{pH}$ values, the cyanobacteria proteins such as biliproteins reduce their charge differential generating lower intermolecular electrostatic repulsion. For this reason, a sharp decrease in protein solubility in aqueous medium was observed with a parallel denaturation in the macromolecule itself.

Regarding color determinations, it was shown that variations in $\mathrm{pH}$ between 3 and 9 did not cause significant variations in the $\mathrm{L}^{*}, \mathrm{a}^{*}$, or $\mathrm{b}^{*}$ indexes, proving the stability of the lightness, redness, and yellowness of the C-PC extract in this $\mathrm{pH}$ range. This is a crucial observation because the solution maintains an attractive appearance in the $\mathrm{pH}$ range assayed for beverages corresponding to blue C-phycocyanin color, 
that is independent of the low absorbance values obtained in comparison with the absorbance in the optimum $\mathrm{pH}$ range (4-8) shown in Fig. $1 b$.

The stability of the blueness of the C-PC extract is related to the high $\mathrm{pH}$ stability of the C-phycocyanin biliprotein. Previous works have studied the $\mathrm{pH}$-induced conformational and functional dynamics of C-phycocyanin isolated from different cyanobacteria by means of absorption, fluorescence, and other common techniques (Bermejo et al. 2002, 2007). C-phycocyanin has a strong functional stability in the $\mathrm{pH}$ range 4-9, with no remarkable changes in absorbance or fluorescence, suggesting the protein's ability of stably transferring energy even at low $\mathrm{pH}$ values.

In light of the above and taking into account the characterization carried out using absorbance, fluorescence, and colorimetry, applications of this blue C-PC extract may be useful in acidic and neutral samples and more specifically in acidic beverages such as those assayed in this study.

Regarding pigmentation of beverage samples using the C-PC extract, it is necessary to highlight that composition of the commercial samples tested should influence the pigmentation results to be obtained, due to the influence of the medium on the coloring capacity of the C-PC extract. According to the ingredients described on the labels of blue beverages found in the market, the most commonly used synthetic dyes are anthraquinone blue (E-130), blue patent V (E-131), indigotine (E-132), and Brilliant blue (E-133). Regarding natural molecules, the only one that is usually found in food and beverages is anthocyanin (E-163) (Moreira et al. 2012; Munier et al. 2014; Carocho et al. 2015).

Therefore, the color given by the blue C-PC extract to standard products assayed in this work was compared to the color of reference products found in grocery stores which contain other types of colorants (commonly brilliant blue E-133). It is important to highlight that the current trend in the food industry for human consumption is favoring the use of natural colorants instead of colorants produced by chemical synthesis.

In global terms, tonic beverages required a smaller volume of C-PC extract in comparison to isotonic beverages and wine to approach the color of commercial products. The products that required the lowest amount of protein were "E" and "F" tonic samples, which obtained staining factors of $15.64 \mathrm{mg} \cdot \mathrm{L}^{-1}$ and $23.41 \mathrm{mg} \cdot \mathrm{L}^{-1}$, respectively. On the other hand, "C" isotonic sample was the product that required the highest amount of protein, with a staining factor of $111.67 \mathrm{mg} \cdot \mathrm{L}^{-1}$. These results show the potential of the $\mathrm{C}-\mathrm{PC}$ extract as natural colorant and the low values of staining factors prove its economic viability.

Regarding viscosity measurements, it is important to highlight that the effect of the extract on texture and viscosity was negligible as the added quantities needed to reproduce the colors of the corresponding products found on the market were lower than $112 \mathrm{mg} \cdot \mathrm{L}^{-1}$ in all experiments. These results are in agreement with previous studies in which astaxanthin was assessed for the pigmentation of dairy products (Mezquita et al. 2015).

In addition to the determination of CIELAB parameters $\left(L^{*}, a^{*}\right.$, and $\left.b^{*}\right)$, the overall color difference $\left(\Delta E^{*} a b\right)$ was calculated denoting the difference in color between two samples: the progressive addition of the C-PC extract to standard commercial products (products without colorant) promotes the gradual decrease of the $\Delta \mathrm{E}^{*} \mathrm{ab}$ value as the color of the standard progressively approaches the color of the commercial product. Regarding the $\Delta \mathrm{E}^{*}$ ab value, the range of $0-0.5$ signifies an imperceptible difference in color, $0.5-1.5$ a slight difference, 1.5-3 a just noticeable difference, 3.0-6.0 a remarkable difference, $6.0-12.0$ an extremely remarkable difference, and above 12.0 a color or shade difference (Kim et al. 2002). It means that a high $\Delta \mathrm{E}^{*}$ ab implies a significant color variation. In this color context, the final sample is the one in which the lowest $\Delta \mathrm{E}^{*}$ ab value is reached. It is important to note that when a $\Delta \mathrm{E}^{*}$ ab value lower than 3 is reached, the color of the sample is nearly the same as that of the reference when viewed by the naked human eye (Mezquita et al. 2015).

Three representative samples were selected as examples for the assayed beverages: observing them, it is possible to infer that the color of each sample was similar to the color of the reference commercial product. Using commercial isotonic, coloring curves of isotonic samples hence suggest that the C-PC coloring extract has good coloring properties as most of the final $\Delta \mathrm{E}^{*}$ ab values were very close to 6 (Fig. 3), allowing samples to reach a color similar to the one of reference commercial products. Nevertheless, the final color presents notable differences, but it could be sufficiently attractive for consumers. Furthermore, it has the additional value of being produced using a natural colorant.

Isotonic beverage " $\mathrm{C}$ " had the highest staining factor (Table 2), and its coloring curve suggests that a large volume of the C-PC extract $(440 \mu \mathrm{L})$ was necessary to get to the final sample (Fig. 3). On the other hand, beverage "D" required the lowest volume of C-PC coloring solution (130 $\mu \mathrm{L}$ ) to achieve the minimum $\Delta \mathrm{E}^{*}$ ab value. Differently, other isotonic beverages required intermediate volumes of the coloring extract to reach a coloring close to the one of commercial products. Generally, sample staining factors are low, proving that attractive colors can be achieved with a fairly low quantity of the C-PC coloring extract.

In the case of using tonic beverages and wine, the coloring curves of tonic samples were dissimilar to the one of the wine sample (Fig. 4).

Tonic samples required very low extract volumes for achieving the desired color. Thus, staining factors were 15.64 and $23.41 \mathrm{mg} \cdot \mathrm{L}^{-1}$ for products "E" and "F", respectively. Differently, the staining factor of sample " $G$ " (wine) 
was quite high compared to tonics samples: its value is $61.76 \mathrm{mg} \cdot \mathrm{L}^{-1}$, and it is from 4 to 2.5 times higher than the staining factor of samples "E" and "F," respectively.

For the development of the stability study, a cold storage period of 11 days was chosen as it was considered adequate. These types of beverages, once opened, are usually consumed within a few days if kept refrigerated. In addition, by working in this refrigerated way, the effect of light and temperature on phycocyanin was minimized. Figure 5 shows the evolution of the different colorimetric parameters as a function of time for the tested beverages. As example, Fig. 5c shows the variations on a* index (redness) for the prepared samples.

Regarding isotonic and tonic samples, it is possible to appreciate very slight variations, with values remaining practically constant from 0 to 11 days. In this case, the tonic sample showed the highest values of a*, while the isotonic sample registered the smallest. On the other hand, the wine sample had a different behavior showing an important increase in $a^{*}$ values during the first two days, going from a value of -11 on the starting day, to a value of -6 at the end of the assayed period. Similarly, $L^{*}$ and $b^{*}$ values for isotonic and tonic samples remain more or less constant, being stable from 0 to 11 days. These parameters change strongly in the case of the wine sample, showing an important variation during the first 2 days. After that, parameters remain constant, showing a global variation of 4 and 8 units for $\mathrm{L}^{*}$ and $\mathrm{b}^{*}$ values, respectively.

The $\Delta \mathrm{E}^{*}$ ab values (Fig. 5a) were very low for tonic and isotonic samples, registering $\Delta \mathrm{E}^{*} \mathrm{ab}=0.25$ and $\Delta \mathrm{E}^{*} \mathrm{ab}=1.0$ (day 1 ), respectively. Despite variations and upward trends, $\Delta \mathrm{E}^{*} \mathrm{ab}$ did not exceed a value of 2.5 for the entire study period. A different trend was observed for the wine, which started with a value of $\Delta \mathrm{E}^{*} \mathrm{ab}=0.4$ at day 1 and concluded with $\Delta \mathrm{E}^{*} \mathrm{ab}=10.0$ at day 11 . However, regardless of its high fluctuation, the difference between day 11 and day 3 was 2.0 for wine, whereas it was 1.75 and 1.10 for isotonic and tonic samples, respectively. Although the behavior of tonic and isotonic beverages is similar, after applying the corresponding statistical test to the stability results, it can be said that there are significant differences between tonic and isotonic beverages (Table 4).

It is well known that $\Delta \mathrm{E}^{*}$ ab values lower than 3.0 cannot be easily detected by the naked human eye and are taken as the same color by consumers (Hong et al. 2004). According to these data, it is deduced that color is quite stable on isotonic and tonic samples. On the other hand, the color of the wine sample was unstable: this behavior can be explained by the alcoholic nature of the solution. Probably, this is not the most suitable environment for C-phycocyanin to keep its colorimetric properties. The phenomenon could be explained by the denaturation effect that alcoholic media have on protein structure.
Furthermore, from the third day onwards, the color of the wine sample began to turn greenish losing the bluish hue of the day it was prepared.

The majority of natural pigments have an antioxidant activity. Although the antioxidant capacity of phycocyanin in the beverage samples used in this work was not determined, stability results could be explained by the antioxidant activity of the phycobiliproteins in general as reported by other authors (Sonani et al. 2014; Jung et al. 2016; Patel et al. 2018). More specifically, the antioxidant effect of phycocyanin was also shown in a previous study, in which the colorant was used in milk products (Kaur et al. 2019).

The outcomes indicate that phycocyanin maintained its stability throughout the refrigerated storage time for two of the three types of beverages assayed without significant changes in any of the three color coordinates. Values of $\Delta \mathrm{E}^{*} \mathrm{ab} \geq 5.0$ were not obtained at any moment during storage of isotonic and tonic samples, with this being the threshold value used by other researchers to indicate the onset of instability (Obón et al. 2009).

In addition to its antioxidant property, another aspect to consider for the application of phycocyanin as natural colorant is the anticancer effect (Fernandes e Silva et al. 2018). This molecule is gaining more importance as it plays a crucial role in preventing or delaying diseases. Overall, artificial antioxidants such as butylhydroxynisole and butylhydroxytoluene pose potential health risks and toxicity: this makes it crucial to substitute them with new harmless natural antioxidants like phycobiliproteins.

\section{Conclusions}

The present study demonstrates that the C-PC extract can be used as a coloring additive for beverages. The color of commercial reference products containing synthetic colorants was compared to the color of samples dyed with the blue C-PC extract. Colors and color differences were measured according to the CIELAB color space, and the colorimetry-based approach was suitable for the purpose of the study. Coloring assays, conducted using a colorimeter, prove that the samples' colors are similar to the colors of reference samples taken from the market. Staining factors determine that low amounts of C-PC are necessary to obtain acceptable samples colors. $\mathrm{pH}$ influences the spectroscopic properties of the protein extract and the stability of C-PC. The optimal $\mathrm{pH}$ range for the stability of the C-PC extract isolated from A. platensis is 4.0-9.0. This study proves that the C-PC coloring extract could be an interesting natural colorant for its attractive coloring properties, and it could expand the list of natural coloring additives now available 
on the market in which the vast majority of blue dyes are of synthetic origin.

Acknowledgements The authors would like to thank the IMADE S.L. for providing the Arthrospira platensis cyanobacteria biomass. Ana Belén García would like to thank the University of Jaén for her predoctoral fellowship. Eleonora Longo would like to thank the University of Jaén and the University of Padova (Italy) for her pre-doctoral fellowship.

Author contribution A.B.G. and E. L. performed the experiments and analyzed the data using the corresponding instruments and software. R.B. conceived and supervised the work and wrote the manuscript, being in charge also of resources, review and editing, and funding acquisition. All authors have read and agreed to the published version of the manuscript.

Funding Open Access funding provided thanks to the CRUE-CSIC agreement with Springer Nature. This research was funded by the University of Jaén (research project PID2019-107816 GB-I00).

Data availability Samples of the compounds are available from the authors.

\section{Declarations}

Conflict of interest The authors declare no competing interests.

Open Access This article is licensed under a Creative Commons Attribution 4.0 International License, which permits use, sharing, adaptation, distribution and reproduction in any medium or format, as long as you give appropriate credit to the original author(s) and the source, provide a link to the Creative Commons licence, and indicate if changes were made. The images or other third party material in this article are included in the article's Creative Commons licence, unless indicated otherwise in a credit line to the material. If material is not included in the article's Creative Commons licence and your intended use is not permitted by statutory regulation or exceeds the permitted use, you will need to obtain permission directly from the copyright holder. To view a copy of this licence, visit http://creativecommons.org/licenses/by/4.0/.

\section{References}

Almeida HHS, Barros L, Barreira JCM, Calhelha R, Heleno S, Sayer C, Miranda CG, Leimann FV, Barreiro MF, Ferreira I (2018) Bioactive evaluation and application of different formulations of the natural colorant curcumin (E100) in a hydrophilic matrix (yogurt). Food Chem 261:224-232

Antelo FS, Costa JAV, Kalil SJ (2008) Thermal degradation kinetics of the phycocyanin from Spirulina platensis. Biochem Eng J 41:43-47

Arad S (Malis), Yaron A (1992) Natural pigments from red microalgae for use in foods and cosmetics. Trends Food Sci Technol 3:92-97

Benedetti S, Rinalducci S, Benvenuti F, Francogli S, Pagliarani S, Giorgi L, Micheloni M, D’Amici GM, Zolla L, Canestrari F (2006) Purification and characterization of phycocyanin from the bluegreen alga Aphanizomenon flos-aquae. J Chromatogr B 833:12-18

Bennett A, Bogorad L (1973) Complementary chromatic adaptation in a filamentous blue-green alga. J Cell Biol 58:419-435
Bermejo R, Felipe MA, Talavera EM, Alvarez-Pez JM (2006) Expanded bed adsorption chromatography for recovery of phycocyanins from the microalga Spirulina platensis. Chromatographia 63:59-66

Bermejo R, Fernández E, Alvarez-Pez JM, Talavera EM (2002) Labeling of cytosine residues with biliproteins for use as fluorescent DNA probes. J Lumin 99:113-124

Bermejo R, Ramos A (2012) Pilot scale recovery of phycocyanin from Spirulina platensis using expanded bed adsorption chromatography. Chromatographia 75:195-204

Bermejo R, Ruiz E, Acien FG (2007) Recovery of B-phycoerythrin using expanded bed adsorption chromatography: scale-up of the process. Enzyme Microb Technol 40:927-933

Bharathiraja S, Seo H, Manivasagan P, Seo H, Manivasagan P, Moorthy MS, Park S, Oh J (2016) In vitro photodynamic effect of phycocyanin against breast cancer cells. Molecules 21:1470

Borowitzka MA (2013) High-value products from microalgae-their development and commercialisation. J Appl Phycol 25:743-756

Campos Assumpção de Amarante M, Cavalcante Braga AR, Sala L, JulianoKalil S (2020) Colour stability and antioxidant activity of C-phycocyanin-added ice creams after in vitro digestion. Food Res Int 137:109602

Carocho M, Barreiro MF, Morales P, Ferreira ICFR (2014) Adding molecules to food, pros and cons: a review on synthetic and natural food additives. Compr Rev Food Sci Food Saf 13:377-399

Carocho M, Morales P, Ferreira ICFR (2015) Natural food additives: Quo vadis? Trends Food Sci Technol 45:284-295

Chen KH, Wang SSS, Show PL, Hsu SL, Chang YK (2019) Rapid and efficient recovery of C-phycocyanin from highly turbid Spirulina platensis algae using stirred fluidized bed ion exchange chromatography. Sep Purif Technol 209:636-645

Chentir I, Kchaou H, Hamdi M, Jridi M, Suming Li, Doumandji A, Nasri M (2019) Biofunctional gelatin-based films incorporated with food grade phycocyanin extracted from the Saharian cyanobacterium Arthrospira sp. Food Hydrocoll 89:715-725

Chowdhury MH, Ray K, Aslan K, Lakowicz JR, Geddes CD (2007) Metal-enhanced fluorescence of phycobiliproteins from heterogeneous plasmonic nanostructures. J Phys Chem C 111:18856-18863

Couteau C, Baudry S, Roussakis C, Coiffard LJM (2004) Study of thermodegradation of phycocyanin from Spirulina platensis. Sci Aliments 24:415-421

Da Silva LP, Pereira E, Prieto MA, Simal-Gandara J, Pires TCSP, Alves MJ, Calhelha R, Barros L, Ferreira ICFR (2019) Rubus ulmifolius Schott as a novel source of food colorant: extraction optimization of coloring pigments and incorporation in a bakery product. Molecules 24:2181

Dewi EN, Kurniasih RA, Purnamayati L (2018) The application of microencapsulated phycocyanin as a blue natural colorant to the quality of jelly candy. IOP Conf Ser Earth Environ Sci 116.https:// doi.org/10.1088/1755-1315/116/1/012047

Fernandes e Silva E, Figueira FS, Cañedo AD, Machado KS, Salgado MTSF, Silva TK, Wagner EF, Mattozo FH, Lima ÉA, Sales-Neto JM, Ferreira VU, Comitre AA, Mascarenhas SR, Kalil SJ, Votto APS (2018) C-phycocyanin to overcome the multidrug resistance phenotype in human erythroleukemias with or without interaction with ABC transporters. Biomed Pharmacother 106:532-542

Galetovic A, Seura F, Gallardo V, Graves R, Cortés J, Valdivia C, Núñez J, Tapia C, Neira I, Sanzana S, Gómez-Silva B (2020) Use of phycobiliproteins from Atacama cyanobacteria as food colorants in a dairy beverage prototype. Foods 9:1-13

García AB, Longo E, Murillo MC, Bermejo R (2021) Using a B-phycoerythrin extract as a natural colorant: application in milk-based products. Molecules 26:297 
Gengatharan A, Dykes GA, Choo WS (2017) The effect of pH treatment and refrigerated storage on natural colourant preparations (betacyanins) from red pitahaya and their potential application in yoghurt. LWT - Food Sci Technol 80:437-445

Glazer AN (1994) Phycobiliproteins - a family of valuable, widely used fluorophores. J Appl Phycol 6:105-112

Hashem MM, Abd-Elhakim YM, Abo-EL-Sooud K, Eleiwa MME (2019) Embryotoxic and teratogenic effects of tartrazine in rats. Toxicol Res 35:75-81

Hong SI, Han JH, Krochta JM (2004) Optical and surface properties of whey protein isolate coatings on plastic films as influenced by substrate, protein concentration, and plasticizer type. J Appl Polym Sci 92:335-343

Hsieh-Lo M, Castillo G, Ochoa-Becerra MA, Mojica L (2019) Phycocyanin and phycoerythrin: Strategies to improve production yield and chemical stability. Algal Res 42:101600

Jespersen L, Strømdahl LD, Olsen K, Skibsted LH (2005) Heat and light stability of three natural blue colorants for use in confectionery and beverages. Eur Food Res Technol 220:261-266

Jung SM, Park JS, Shim HJ, Kwon YS, Kim HG, Shin HS (2016) Antioxidative effect of phycoerythrin derived from Grateloupia filicina on rat primary astrocytes. Biotechnol Bioprocess Eng 21:676-682

Kannaujiya VK, Sundaram S, Sinha RP (2017) Phycobiliproteins: Recent developments and future applications. Springer, Singapore

Kaur S, Khattar JIS, Singh Y, Singh Y, Singh DP, Ahluwalia AS (2019) Extraction, purification and characterisation of phycocyanin from Anabaena fertilissima PUPCCC 410.5: as a natural and food grade stable pigment. J Appl Phycol 31:1685-1696

Kim S, Park JB, Hwang IK (2002) Quality attributes of various varieties of Korean red pepper powders (Capsicum anпиum L.) and color stability during sunlight exposure. J Food Sci 67:2957-2961

Leong HY, Su CA, Lee BS, Lan JCW, Law CL, Chang JS, Show PL (2019) Development of Aurantiochytrium limacinum SR21 cultivation using salt-rich waste feedstock for docosahexaenoic acid production and application of natural colourant in food product. Bioresour Technol 271:30-36

Lobo FATF, Silva V, Domingues J, Rodrigues S, Costa V, Falcão D, Araújo KGL (2018) Inclusion complexes of yellow bell pepper pigments with $\beta$-cyclodextrin: preparation, characterisation and application as food natural colorant. J Sci Food Agric 98:2665-2671

MacColl R (1998) Cyanobacterial phycobilisomes. J Struct Biol 124:311-334

Mahmoud NH, Org WE (2006) Toxic effects of the synthetic food dye Brilliant Blue on liver, kidney and testes functions in rats. J Egypt Soc Toxicol 34:77-84

Mezquita PC, Huerta BEB, Ramírez JCP, Hinojosa CPO (2015) Milks pigmentation with astaxanthin and determination of colour stability during short period cold storage. J Food Sci Technol 52:1634-1641

Mohammadi-Gouraji E, Soleimanian-Zad S, Ghiaci M (2019) Phycocyanin-enriched yogurt and its antibacterial and physicochemical properties during 21 days of storage. LWT - Food Sci Technol 102:230-236

Montibeller MJ, de Lima MP, Tupuna-Yerovi DS, Rios AO, Manfroi V (2018) Stability assessment of anthocyanins obtained from skin grape applied in kefir and carbonated water as a natural colorant. J Food Process Preserv 42:e13698

Moreira I de O, Passos TS, Chiapinni C, Silveira GK, Souza JCM, CocaVellarde LG, Deliza R, Araújo KGL (2012) Colour evaluation of a phycobiliprotein-rich extract obtained from Nostoc PCC9205 in acidic solutions and yogurt. J Sci Food Agric 92:598-605

Munier M, Jubeau S, Wijaya A, Morançais M, Dumay J, Marchal L, Joauen P, Fleurence J (2014) Physicochemical factors affecting the stability of two pigments: R-phycoerythrin of Grateloupia turuturu and B-phycoerythrin of Porphyridium cruentum. Food Chem 150:400-407

Newsome AG, Culver CA, Van Breemen RB (2014) Nature's palette: the search for natural blue colorants. J Agric Food Chem 62:6498-6511

Ngamwonglumlert L, Devahastin S, Chiewchan N, Raghavan GSV (2020) Color and molecular structure alterations of brazilein extracted from Caesalpinia sappan $\mathrm{L}$. under different $\mathrm{pH}$ and heating conditions. Sci Rep 10:12836

Niccolai A, Venturi M, Galli V, Pini N, Rodolfi L, Biondi N, D’Ottavio M, Batista AP, Raymundo A, Granchi L, Tredici R (2019) Development of new microalgae-based sourdough "crostini": functional effects of Arthrospira platensis (Spirulina) addition. Sci Rep 9:19433

Obón JM, Castellar MR, Alacid M, Fernández-López JA (2009) Production of a red-purple food colorant from Opuntia stricta fruits by spray drying and its application in food model systems. J Food Eng 90:471-479

Otálora MC, de Jesús BH, Perilla JE, Osorio C, Nazareno MA (2019) Encapsulated betalains (Opuntia ficus-indica) as natural colorants Case Study: Gummy Candies. LWT 103:222-227

Patel A, Pawar R, Mishra S, Sonawane S, Ghosh PK (2004) Kinetic studies on thermal denaturation of C-phycocyanin. Indian J Biochem Biophys 41:254-257

Patel SN, Sonani RR, Jakharia K, Bhastana B, Patel HM, Chaubey MG, Singh NK, Madamwar D (2018) Antioxidant activity and associated structural attributes of Halomicronema phycoerythrin. Int J Biol Macromol 111:359-369

Pereira T, Barroso S, Mendes S, Amaral RA, Dias JR, Baptista T, Saraiva JA, Alves NM, Gil MM (2020) Optimization of phycobiliprotein pigments extraction from red algae Gracilaria gracilis for substitution of synthetic food colorants. Food Chem 321:126688

Pires TCSP, Dias MI, Carocho M, Barreira JCM, Santos-Buelga C, Barros L, Ferreira ICFR (2020) Extracts from: Vaccinium myrtillus L. Fruits as a source of natural colorants: chemical characterization and incorporation in yogurts. Food Funct 11:3227-3234

Prasanna R, Sood A, Jaiswal P, Nayak S, Gupta V, Chaudhary V, Joshi M, Natarajan C (2010) Rediscovering cyanobacteria as valuable sources of bioactive compounds (Review). Appl Biochem Microbiol 46:119-134

Ramos A, Acién FG, Fernández-Sevilla JM, González CV, Bermejo R (2011) Development of a process for large-scale purification of C-phycocyanin from Synechocystis aquatilis using expanded bed adsorption chromatography. J Chromatogr B 879:511-519

Rimbau V, Camins A, Pubill D, Sureda FX, Romay C, González R, Jiménez A, Escubedo E, Camarasa J, Pallàs M (2001) C-phycocyanin protects cerebellar granule cells from low potassium/serum deprivation-induced apoptosis. Naunyn Schmiedebergs Arch Pharmacol 364:96-104

Rimbau V, Camins A, Romay C, González R, Pallás M (1999) Protective effects of C-phycocyanin against kainic acid-induced neuronal damage in rat hippocampus. Neurosci Lett 276:75-78

Rito-Palomares M, Nuez L, Amador D (2001) Practical application of aqueous two-phase systems for the development of a prototype process for c-phycocyanin recovery from Spirulina maxima. J Chem Technol Biotechnol 76:1273-1280

Romay C, Ledón N, González R (1998) Further studies on anti-inflammatory activity of phycocyanin in some animal models of inflammation. Inflamm Res 47:334-338

Samsonoff WA, MacColl R (2001) Biliproteins and phycobilisomes from cyanobacteria and red algae at the extremes of habitat. Arch Microbiol 176:400-405

Sekar S, Chandramohan M (2008) Phycobiliproteins as a commodity: trends in applied research, patents and commercialization. J Appl Phycol 20:113-136 
Sinha RP, Singh G, Kesheri M, Kannaujiya VK (2011) biotechnological potentials of phycobiliproteins. Int J Pharma Bio Sci 4:446-454

Sonani RR (2016) Recent advances in production, purification and applications of phycobiliproteins. World J Biol Chem 7:100

Sonani RR, Patel S, Bhastana B, Jakharia K, Chaubey MG, Singh NK, Madamwar D (2017) Purification and antioxidant activity of phycocyanin from Synechococcus $s p$. R42DM isolated from industrially polluted site. Bioresour Technol 245:325-331

Sonani RR, Singh NK, Kumar J, Kumar J, Thakar D, Madamwar D (2014) Concurrent purification and antioxidant activity of phycobiliproteins from Lyngbya sp. A09DM: An antioxidant and anti-aging potential of phycoerythrin in Caenorhabditis elegans. Process Biochem 49:1757-1766

Tavanandi HA, Mittal R, Chandrasekhar J, Raghavarao KSMS (2018) Simple and efficient method for extraction of C-Phycocyanin from dry biomass of Arthrospira platensis. Algal Res 31:239-251

Publisher's note Springer Nature remains neutral with regard to jurisdictional claims in published maps and institutional affiliations. 